\title{
ESPAÇOS RURAIS
}

\section{BRASILEIROS NA ARTE NÄIF \\ DE MARCELO SCHIMANESKI: \\ DESENVOLVIMENTO TERRITORIAL E MULTIFUNCIONALIDADE DA AGRICULTURA}

\section{Gabriela Maria Leme Trivellato}

Escola Superior de Agricultura Luiz de Queiroz/Universidade de São Paulo. Piracicaba, São Paulo - Brasil

gabriela.mltrivellato@outlook.com

Recebido em 01/10/2020. Aprovado em 18/1 1/2020.

DOI: $\underline{\text { dx.doi.org/10.5380/guaju.v6i2.76953 }}$

\section{Resumo}

Este artigo se propõe a pensar a utilização da arte como ferramenta em prol da preservação ambiental e cultural dos espaços rurais, dedicados à agricultura familiar brasileira. Tratamos especificamente do gênero de arte Naïf e do trabalho do artista paranaense Marcelo Schimaneski. Na arte Naïf de Marcelo Schimaneski são apresentadas cenas do cotidiano de espaços rurais na região das cidades paranaenses de Ponta Grossa e Olarias. Partimos da hipótese de que é possível encontrarmos, em suas obras, elementos que retratam a multifuncionalidade da agricultura nesses espaços. A ideia de multifuncionalidade da agricultura (MFA), inserida na discussão sobre o desenvolvimento sustentável, valoriza a presença dos seres humanos nos espaços rurais, podendo contribuir para a manutenção dos serviços ecossistêmicos, da beleza das paisagens, da qualidade de vida, das relações sociais, do alimento de qualidade, da preservação da natureza. Acreditamos que as obras Naïf desse artista valorizam a identidade dos lugares retratados, podendo corroborar com a preservação ambiental e cultural de espaços rurais como os retratados.

Palavras-chave:preservação ambiental; serviços ecossistêmicos; desenvolvimento sustentável. 


\title{
Brazilian Rural Spaces in The Näif Art of Marcelo Schimaneski: Territorial Development and Multifunctionality of Agriculture
}

\begin{abstract}
This article proposes to think about the use of art as a tool in favor of environmental and cultural preservation of rural spaces, dedicated to Brazilian family farming. We specifically deal with the Naïf art genre and with the artist Marcelo Schimaneski's work, from Paraná State, Brazil. In Marcelo Schimaneski's Naïf art are presented everyday life scenes in rural spaces on the cities of Ponta Grossa and Olarias region, in Paraná State. Our hypothesis is that it is possible to find elements that portray the multifunctionality of agriculture in these spaces. The idea of multifunctionality in agriculture (MFA), inserted in the discussion on sustainable development, values the presence of human beings in rural areas, being able to contribute to the maintenance of ecosystem services, beauty of the landscapes, life quality, social relations, food quality, nature preservation. We believe that the Naïf works of this artist value the identity of the places portrayed and can corroborate to environmental and cultural preservation of the rural spaces such as those portrayed.
\end{abstract}

Keywords: environmental preservation; ecosystem services; sustainable development. 


\section{Introdução}

Com o objetivo de "abrir espaço" para um grupo de artistas que não conseguiam expor suas obras nas consagradas salas de arte moderna e contemporânea, o Sesc Piracicaba criou, em 1986, dentro do projeto "Cenas da Cultura Caipira", a "Mostra Nacional de Arte Ingênua e Primitiva". Estes artistas eram considerados "ingênuos", "espontâneos". Em 1992, a mostra transforma-se na primeira Bienal Naïfs do Brasil (SESC SP, 2018). A 14ª Bienal Naïfs do Brasil ocorreu de 18 de agosto a 25 de novembro, no Sesc Piracicaba/SP, sob o título “Daquilo que escapa". Dentre as obras selecionadas, encontravam-se "late clube" e "Bela vista", do artista Marcelo Schimaneski (SESC SP, 2018; SESC PIRACICABA, 2018). Schimaneski, em suas obras, retrata a cidade de Ponta Grossa/PR e cenas de sua infância em chácaras e na região de Olarias/PR (PG CULTURA, 2011c). Este artigo foi inspirado pelo contato com estas obras de Marcelo Schimaneski, em visita à 14ª Bienal Naïfs do Brasil, em 24 de agosto de 2018, no Sesc Piracicaba/SP.

Figura 1 - "Bela Vista", de Marcelo Schimaneski. Foto tirada em 24 de agosto de 2018, em visita à 14a Bienal Naïfs do Brasil, Sesc Piracicaba/SP.

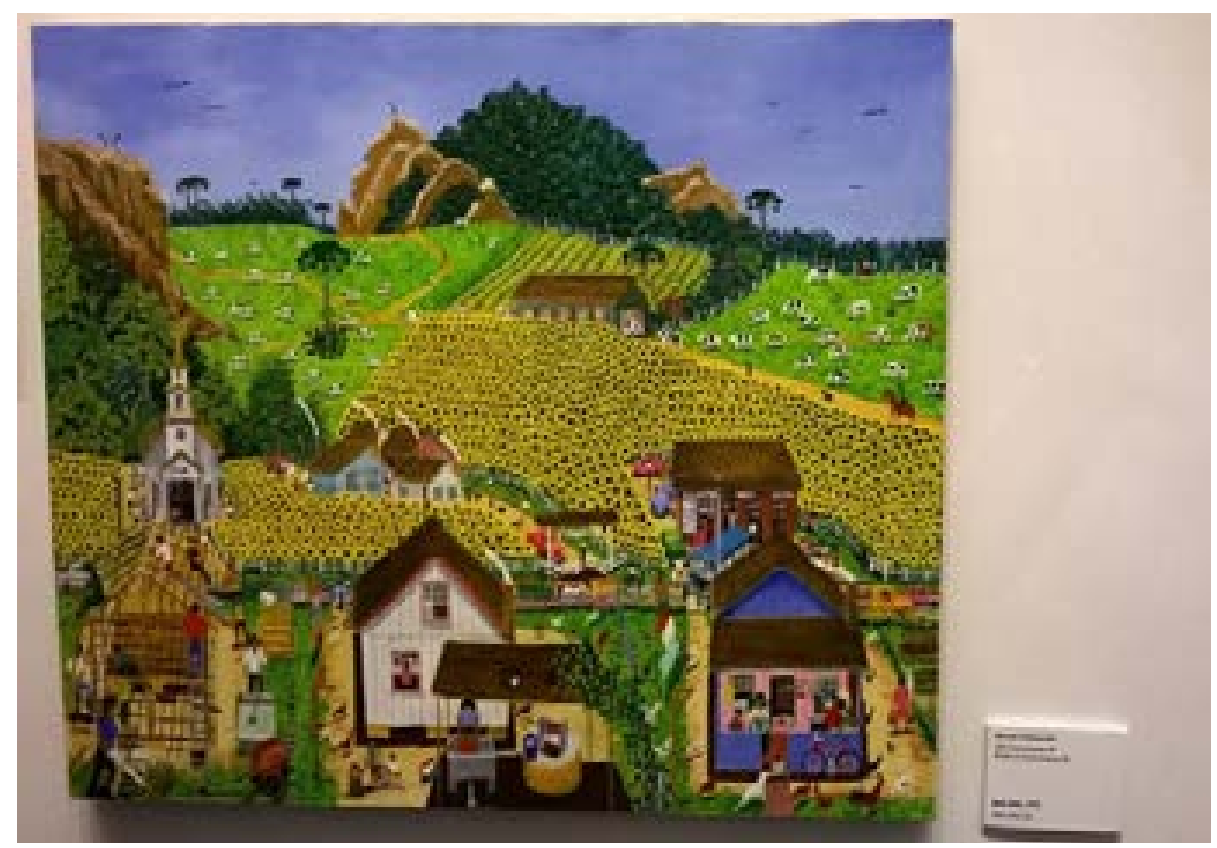

Fonte: acervo pessoal AUTOR 1. 
Figura 2 - "late clube", de Marcelo Schimaneski. Foto tirada em 24 de agosto de 2018, em visita à 14a Bienal Naïfs do Brasil, Sesc Piracicaba/SP.

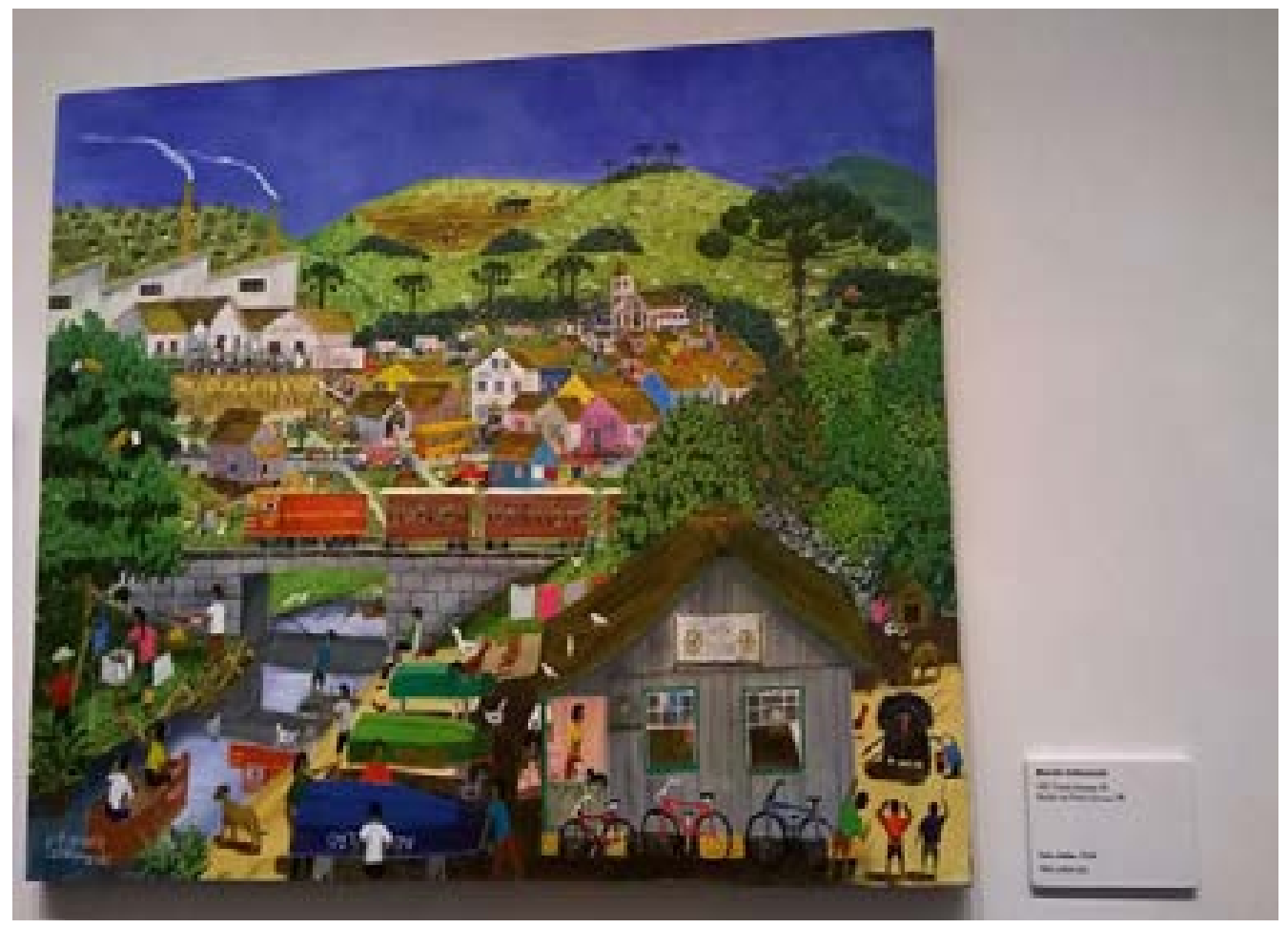

Fonte: acervo pessoal AUTOR 1.

Acreditamos que é possível encontrar elementos em prol da multifuncionalidade da agricultura (MFA) na arte Naïf de Marcelo Schimaneski, sobretudo no que tange às quatro expressões da MFA na realidade rural brasileira, apontadas por Maria José Carneiro e Renato Maluf (2003): a) reprodução socioeconômica das famílias rurais; b) promoção da segurança alimentar das próprias famílias rurais e da sociedade; c) manutenção do tecido social e cultural; d) preservação dos recursos naturais e da paisagem rural.

Diante da hipótese de que é possível encontrarmos na arte Naif de Marcelo Schimaneski elementos que favorecem a MFA, nosso objetivo é discutirmos neste artigo em que medida as obras Naïf desse artista valorizam a identidade dos lugares retratados, podendo corroborar com a preservação ambiental e cultural de espaços rurais de agricultura familiar brasileiros como estes. 


\title{
Desenvolvimento Territorial e Multifuncionalidade da Agricultura
}

Conforme Cazela, Bonnal e Maluf (2009), o desenvolvimento territorial abrange "um inventário dos recursos locais (...) realizado com imaginação, capaz de transformar aspectos negativos em novos projetos de desenvolvimento" (CAZELLA; BONNAL; MAULF, 2009, p. 39). Nesse sentido, defendem que o desenvolvimento territorial associa-se a um processo no qual os "valores simbólicos passem a desempenhar um papel de recursos socioeconômicos" op. cit, p. 39). Trata-se de que os atores envolvidos no processo de favorecimento do desenvolvimento territorial - "pesquisadores, associações civis, empresas privadas e órgãos públicos" - trabalhem de tal modo que "aproveitem a 'atmosfera' propícia à geração de iniciativas inusitadas" (CAZELLA; BONNAL; MALUF, 2009, p. 39).

\begin{abstract}
Ao direcionar a atenção para o que se nomeou de 'funções não diretamente produtivas da agricultura', (...) [a MFA] promove um recorte analítico que favorece uma percepção holística (e não setorial) da sociedade, revelando a importância e buscando significados de atividades e relações sociais que, até então, estavam à margem das análises econômicas e das lentes dos formuladores de políticas públicas (CARNEIRO; MALUF, 2005, p. 56).
\end{abstract}

A modernização da agricultura brasileira favoreceu a concentração fundiária, a degradação ambiental e a exclusão social (SCHNEIDER, 2002). Na contramão disto, na MFA, a ideia de agricultura associa-se a "um espaço de vida, 'produtor' de externalidades e bens públicos" (FRANCO ALVES; MALAGODI, 2014, p. 117). A MFA, para Carneiro e Maluf (2005), "permite resgatar a importância do conjunto de contribuições da agricultura para a dinâmica econômico-social dos territórios (...) Sua maior contribuição estaria, portanto, na possibilidade de (...) perceber a agricultura na sua relação com as outras esferas do social" (CARNEIRO; MALUF, 2005, p. 56).

\footnotetext{
O território está condicionado, sobretudo, a uma organização espacial e temporal mediada por atores sociais que podem atuar de forma individual e/ou coletiva, ocupando determinados pontos no espaço de acordo com suas intencionalidades. Tais pontos são interligados em diferentes escalas e estabelecem relações entre si, resultando em uma dinâmica complexa de redes de circulação e comunicação. Podemos exemplificar através da nossa própria vida cotidiana, que é mediada por práticas sociais que acabam estabelecendo relações entre si no tempo e no espaço. Dessa forma, ao estabelecer a nossa territorialidade estamos também constituindo nossas ações através de redes, nós e malhas que possibilitam uma maior fluidez no território, incluindo-se aí uma expansão das nossas redes de sociabilidade (COLASANTE, 2015, p. 3).
} 
O conceito de MFA surge na Europa, no âmbito do debate sobre o desenvolvimento sustentável, com o objetivo de apontar que a agricultura tinha funções sociais essenciais. Tratavam-se da: preservação do meio ambiente; oferta de emprego rural; articulação entre produtor rural, sua produção e aspectos culturais e sociais do seu território; manutenção de um modo de vida e produção que garantissem a segurança alimentar das famílias produtoras, a preservação ambiental e a manutenção do patrimônio cultural (refere-se ao estilo arquitetônico das casas e às manifestações culturais) (CARNEIRO; MALUF, 2005, p. 43).

Para Carneiro e Maluf (2005), a MFA pode funcionar como instrumento analítico para políticas públicas, no entanto, reconhecem a necessidade de "adaptações teóricas e instrumentais dessa noção para aplicá-la à realidade brasileira" (CARNEIRO; MALUF, 2005, p. $56)$.

\begin{abstract}
As restrições ao acesso à terra, responsáveis, entre outros fatores, pela desigualdade social do mundo rural brasileiro; as dificuldades na institucionalização e na efetivação das instâncias de negociação (e 'concertação') social; as carências na constituição e no reconhecimento legal do agricultor como profissional, são alguns dos fatores que demandam essa adaptação (op. cit., 2005, p. 56).
\end{abstract}

Por outro lado, Carneiro e Maluf (2005) acreditam que a MFA viabiliza a análise de "diversos elementos e fatos sociais que compõem o universo social do mundo rural, favorecendo a compreensão da inserção de diferentes tipos de famílias rurais nesse universo" (CARNEIRO; MALUF, 2005, p. 56). Nesse sentido, a MFA legitima "formas de inserção social e de fontes de renda que normalmente ficam fora dos quadros analíticos hegemônicos" (op. cit., 2005, p. 56). Não se trata, no entanto, de "apenas inserir novas formas de participação econômica de segmentos da população rural ou de buscar significados econômicos para certas atividades que são classicamente consideradas como pertencentes ao meio 'sóciocultural'" (CARNEIRO; MALUF, 2003, p. 56).

As identidades territoriais não são apenas um elemento dado na forma de uma representação cultural mas resultado de um processo complexo de continuidade e descontinuidade, pois, envolvem aspectos subjetivos e objetivos nos quais podem ocorrer intencionalidades, como é o caso da ideologia do Estado que acaba impondo certos valores e símbolos nacionais para determinada sociedade ou podem ser espontâneos quando acarretam sentimentos de pertencimento e afetividade com o lugar. Assim, somos constantemente redefinidos na nossa identidade territorial, pois, a cultura que é o elo principal nesse conceito, acaba se modificando a todo instante e, mesmo que as tradições sejam preservadas, não se consegue reproduzir os aspetos culturais antepassados de forma exatamente idêntica (COLASANTE, 2015, p. 5). 
Para Carneiro e Maluf (2005), a noção de multifuncionalidade da agricultura (MFA) propõe um projeto de sociedade no qual "as diversas dimensões da atividade agrícola" devam estar presentes. Para isso, os modelos de desenvolvimento adotados devem ter base no território, "de modo a contemplar a diversidade das realidades locais". Para eles, a MFA defende que o"papel da agricultura e da participação das famílias rurais no desenvolvimento local" sejam vistos de forma integrada pelas diversas esferas da sociedade (CARNEIRO; MALUF, 2005, p. 56).

Quanto às quatro expressões da multifuncionalidade da agricultura (MFA) na realidade rural brasileira, apontadas por Maria José Carneiro e Renato Maluf (2003), lembramos a "reprodução socieconômica das famílias rurais", que remete às possibilidades de geração de trabalho e renda no meio rural que permitam às familias rurais manterem-se no campo em condições dignas (CARNEIRO; MALUF, 2003, p. 137).

A "promoção da segurança alimentar das próprias famílias rurais e da sociedade" aponta para a garantia de segurança alimentar quanto à disponibilidade e acesso aos alimentos quanto a sua qualidade (CARNEIRO; MALUF, 2003, p. 142).

Na ideia de "manutenção do tecido social e cultural", defende-se que, ao definir-se como agricultor e assumir esta condição, os membros destas famílias inserem-se socialmente e definem seus padrões de sociabilidade (2003, p. 144). Com isso, destaca-se a importância das relações sociais para garantir o fortalecimento político e econômico das famílias rurais brasileiras, como destacado em trabalhos como os de Brandengburg (2008), Ferreira e Zanoni (2008), Bergamasco e Bueno (2008), Abramavoy (1981) e Moruzzzi Marques, De Lucas e Trivellato (2017). Portanto, a sua existência social e reconhecimento social estão atrelados à agricultura. Isto implica que a retirada desta condição afeta profundamente a auto-estima dessas pessoas e suas relações sociais.

\footnotetext{
A relação entre agricultura e identidade social, num quadro de redução da importância econômica da produção mercantil de alimentos, exige a valorização de aspectos não comumente considerados peloas analistas, tais como os modos de vida, as relações com a natureza, as relações com parentes e vizinhos (sociabilidade) e a produção de alimentos para a própria família. (...) a atividade agrícola desempenhada pelas famílias rurais [cumpre] (...) um papel importante na manutenção das respectivas comunidades e, portatno, dos seus respectivos componentes sociais e culturais. (...) No Brasil, (...) a permanência dos agricultores no campo [torna-se] fundamental para a preservação de redes sociais e como condição de cidadania (CARNEIRO; MALUF, 2003, p. 144-145).
} 
Quanto à "preservação dos recursos naturais e da paisagem rural", são considerados os danos ou contribuições da agricultura para a paisagem rural e o patrimônio natural (CARNEIRO; MALUF, 2003, p. 148). Estes irão afetar os demais aspectos, uma vez que estes agricultores dependem do espaço rural e de seus recursos para produzir.

Sobre os termos MFA, pluriatividades e atividades para-agrícolas, tratando-se de termos facilmente confundidos, o que implica em interpretações errôneas em relação à ideia de MFA, consideramos a importância de diferenciarmos.

Resumimos o entendimento de MFA, na realidade brasileira, sob a ótica de Carneiro e Maluf (2003), considerando os quatro principais papeis.

As pluriatividades referem-se às atividades agrícolas realizadas "em tempo parcial [associadas], sobretudo, ao assalariamento em circunstâncias nas quais existam dinâmicos mercados de trabalho industrial ou de serviços" (LACERDA; MORUZZI MARQUES, 2008, p. 154). Tratam-se de estratégias de reprodução socioeconômica, geradas no contexto da modernização da agricultura brasileira e que teriam sido adotadas pelas unidades familiares de produção agrícola para se adaptarem a um cenário socioeconômico desfavorável (SCHNEIDER, 2002).

Logo, pluriatividades e MFA diferenciam-se e distanciam-se (LAURENT, 2000) na medida em que a noção de MFA alinha-se ao debate relativo ao desenvolvimento sustentável (RÉMY, 2005), enquanto as pluriatividades caracterizam-se como "uma acomodação desconfortável num terreno hostil" (LACERDA; MORUZZI MARQUES, 2008, p. 153).

As atividades para-agrícolas, por sua vez, fazem parte do contexto de uma agricultura que cumpre com as suas múltiplas funções, pois abrangem o exercício de diferentes atividades pelos agricultores em tempo integral nas suas unidades (ROUX; FOURNEL, 2003). Devem, portanto, estar inseridas na cadeia produtiva. Representam o beneficiamento, a entrega e a comercialização de produtos, as atividades em agroindústria, o turismo rural ou a preservação ambiental, desde que estejam relacionadas diretamente à unidade familiar de produção (LACERDA; MORUZZI MARQUES, 2008, p. 154).

\section{Arte Naiif e Desenvolvimento Territorial}

A arte Naîf consiste numa "busca individual de expressar a beleza e o fascínio da 
realidade e do cosmo por meio de pinturas que espraiam a liberdade e a nobreza do artista, em sua simplicidade e rusticidade" (DOS SANTOS; DE OLIVEIRA MOLINARI, 2017, p. 5). Conforme Alma Lorena del Cid (2010),

El arte que es llamado por muchos naif también es reconocido con otros nombres, como por ejemplo, pintura primitivista, arte naïve, pintura ingenua, pintura folk, arte popular y pintura maya. Dichas obras son autorepresentaciones que hacen los pintores acerca de distintas facetas de la vida cotidiana, tanto individual como de su comunidad. En las pinturas se muestran realidades que la historia va configurando; su elaboración se da en diversos países, cada uno con su sello personal y representando realidades diferentes. (DEL CID, 2010, p. 17)'.

A arte Naïf surge na França, no período do Romantismo, final do século XIX. Tratase de um contexto no qual a Europa é marcada por uma mudança, "uma transição entre os séculos", onde nasce um novo poder: a burguesia (DOS SANTOS; DE OLIVEIRA MOLINARI, 2017, p. 4-5). O termo "Naïf" tem origem francesa. Deriva do latim "nativus", associando-se às ideias de algo natural, ingênuo ou primitivo. Nas artes, teria sido usado em referência à pintura do artista modernista francês Henri Rousseau (1844-1910) (SESC SP, 2018).

\begin{abstract}
Considerado o precursor da Arte Naif, [Henri Rousseau] (...) buscava inspiração para suas telas no cenário parisiense, frequentava o Jardim Botânico, observava a dinâmica natural dos seres que lá habitavam e, envolvido por uma habilidade artística peculiar, reproduzia em suas telas trabalhos de uma beleza imensurável, mas que não o excluíam de sofrer as sanções e a dureza das críticas dos especialistas em arte da época, que o repeliam pelo fato de conceberem a expressão desse artista como inválida, dados as conveniências estéticas daquele período (DOS SANTOS; DE OLIVEIRA MOLINARI, 2017, p. 5).
\end{abstract}

A arte Naïf no Brasil ganha ênfase no século XX. "Na versão brasileira, essa arte reflete nas telas dos artistas, o panorama social do país, por meio de cores fortes, retratando a exuberância do Brasil" (DOS SANTOS; DE OLIVEIRA MOLINARI, 2017, p. 6). A arte Naïf caracteriza-se pelo"uso de cores fortes, que ilustram os cenários, os quais são representativos dos panoramas naturais e sociais da dinâmica das comunidades humanas, em diferentes períodos históricos" (DOS SANTOS; DE OLIVEIRA MOLINARI, 2017, p. 4). A arte Naïf volta seu

1 Em tradução livre para o Português: A arte por muitos chamada de Naïf também é reconhecida por outros nomes, como pintura primitivista, arte ingênua, pintura ingênua, pintura popular, arte popular e pintura maia. Essas obras são autorrepresentações feitas pelos pintores acerca de diferentes facetas da vida cotidiana, tanto individual quanto comunitária. Nas pinturas são retratadas realidades configuradas pela história; são elaboradas em diferentes países, cada um com sua marca pessoal, representando diferentes realidades. 
olhar para a simplicidade da vida das pessoas.

\begin{abstract}
A pintura de caráter Naïf não compreende um estilo de arte, mas uma criação estética voltada ao desapego e à informalidade, uma obra pintada pela'alma' do artista, que faz uso de traços expressivos e apresenta temáticas voltadas à natureza e à dinâmica social vivenciada pelas massas (DOS SANTOS; DE OLIVEIRA MOLINARI, 2017, p. 4).
\end{abstract}

Para Del Cid (2010), o território é marcado pelas características específicas da cultura do povo que ali habita. A arte Naîf, ao dedicar-se à expressão das singularidades locais da cultura popular, atrai o olhar das pessoas para estas comunidades. Nesse sentido, considerase o papel da arte Naif na promoção do turismo, constituindo-se como ferramenta de desenvolvimento territorial (DEL CID, 2010). Por outro lado, além de atrair turistas e recursos, a arte Naïf favorece a valorização e preservação da cultura local (DEL CID, 2010).

Del Cid (2011) defende que a construção local do território é responsabilidade das pessoas que o ocupam. Isto se expressa na identidade local. “Un tema ineludible al hablar de desarrollo territorial es el relativo a identidad. El conocimiento de las expresiones identitarias permitirá comprender en gran medida la forma en que se desarrolla un territorio" 2 (DEL CID, 2010, p. 19). Ou seja, reconhece-se a identidade local por meio dos fatores que identificam este grupo de pessoas, sendo os mais representativos: principal idioma utilizado, artesanatos, comidas, festivais, formas de arte, paisagens. Para Del Cid (2010), as obras Naïfs tratam-se de representações feitas pelos artistas acerca das diferentes facetas da vida cotidiana, tanto dele mesmo como da sua comunidade. Nelas, apresentam-se realidades configuradas pelo passar da história nas comunidades, representando identidades étnicas.

No âmbito do desenvolvimento local, no artigo "El arte Naïf como generador de desarrollo territorial" (arte Naïf como promotora de desenvolvimento territorial, tradução livre), Alma Lorena del Cid (2010) associa desenvolvimento territorial e arte Naïf. Para Claude Courlet, Bernard Pecqueur e Bernard Soulage (1993), o território resulta de uma construção social. Sobre a noção de território, Ademir Cazella, Philippe Bonnal e Renato Maluf (2009) apontam:

O território é uma unidade ativa de desenvolvimento que dispõe de recursos específicos e não transferíveis de uma região para outra. Trata-se de recursos materiais ou não, a exemplo de um saber-fazer original, em geral, ligado à

2 Em tradução livre para o Português: Uma questão incontornável quando se fala em desenvolvimento territorial é a identidade. O conhecimento das expressões identitárias nos permitirá compreender em grande medida a forma como um território se desenvolve. 
história local. A consequência disso é que não se pode valorizar esse tipo de recurso noutro lugar. O território não é, portanto, só uma realidade geográfica ou física, mas uma realidade humana, social, cultural e histórica. Isso significa que as mesmas condições técnicas e financeiras não geram os mesmos efeitos econômicos em termos de desenvolvimento em dois territórios diferentes. (...) O que cria o território é o sistema de atores locais (CAZELLA; BONNAL; MALUF, 2009, p. 39).

\section{Multifuncionalidade da Agricultura e Preservação Ambiental}

No documento Millennium Ecosystem Assessment (MEA) do World Resources Institute, deWashinton, DC (ASSESSMENT, 2005a;2005b), são apresentados 37 serviços ecossistêmicos. Estes foram elencados em quatro categorias: 1. serviços de provisão; 2 . serviços regulatórios; 3. serviços culturais, como recreação, prazer estético e realização espiritual; 4. serviços de suporte, que incluem formação do solo, fotossíntese e ciclagem de nutrientes (MEA, 2005a, p. 19). Os "serviços de provisão" abarcam o fornecimento/obtenção de alimentos, água, madeira e fibra. "Serviços regulatórios" referem-se à regulação do clima, inundações, doenças e qualidade da água. Os "serviços culturais" incluem recreação, prazer estético e realização espiritual. Os "serviços de suporte" tratam da formação do solo, fotossíntese e ciclagem de nutrientes (MEA, 2005a, p. 19).

Para a Millennium Ecosystem Assessment (MEA), "os serviços ecossistêmicos são os benefícios que as pessoas obtém dos ecossistemas"(TRIVELLATO; DOSSANTOS, 2019, p. 104). Na MEA, estabelece-se uma "conexão entre biodiversidade, serviços ecossitêmicos e bemestar humano. Ela reconhece que os fatores que condicionam o bem-estar humano estão direta ou indiretamente ligados à biodiversidade e os serviços ecossitêmicos" (TRIVELLATO; DOS SANTOS, 2019, p. 105).

As culturas humanas, seus sistemas de conhecimento, religiões, valores patrimoniais, interações sociais e serviços de utilidade (como diversão estética, recreação, realização artística e espiritual e desenvolvimento intelectual) são fortemente influenciados pelos ecossistemas e, alterações podem gerar impactos significativos na identidade cultural e estabilidade social das pessoas (MEA, 2005b). A degradação dos ecossistemas no último século, porém, reduziu a sua a capacidade de fornecer benefícios culturais, fazendo com que as pessoas deixassem de reconhecê-los e valorizá-los. Tratam-se de mudanças sociais e ecossistêmicas, como o declínio do número de bosques sagrados e outras áreas protegidas e o desaparecimento de línguas e de conhecimentos tradicionais. Para a MEA, a rápida perda de ecossistemas e paisagens culturalmente valiosos pode contribuir para rupturas sociais e marginalização de sociedades (TRIVELLATO; DOS SANTOS, 2019, p. 105). 
Em “O Papel dos Seres Humanos na Manutenção dos Ecossistemas", Trivellato e Dos Santos (2019) defendem que "desprezar os serviços e benefícios dos ecossistemas implica no comprometimento do bem-estar dos seres humanos" (TRIVELLATO; DOS SANTOS, 2019, p. 115).

\begin{abstract}
Acreditamos que a espécie humana é fundamentalmente dependente do fluxo de serviços ecossistêmicos para ser protegida contra as mudanças ambientais e que a rápida perda de ecossistemas e paisagens culturalmente valiosos pode contribuir para rupturas sociais e marginalização de sociedades. Nesse sentido, acreditamos que os povos indígenas e agricultores familiares constituem grupos humanos com grande potencial para contribuir na manutenção dos serviços ecossistêmicos, na medida em que seus modos de vida e costumes estão culturalmente atrelados à preservação dos ecossistemas (TRIVELLATO; DOS SANTOS, 2019, p. 115).
\end{abstract}

Para Andrade et al. (2014), os agricultores podem contribuir para a conservação da biodiversidade local e para o desenvolvimento de agriculturas sustentáveis. Ao permanecem no meio rural, constituem laços de identificação sociocultural com o local, o que pode fomentar o "desenvolvimento de políticas públicas de sustentabilidade, de conservação e programas de Educação Ambiental que incluam a percepção e o conhecimento dos agricultores nos territórios e contextos rurais, em um processo emancipatório de participação e empoderamento" (ANDRADE et al, 2014, p. 2).

Para Angela Duarte Damasceno Ferreira (2002), ao permanecerem no espaço rural, em seus estabelecimentos agrícolas, os indivíduos mantem um "ponto de referência e pertencimento" que permite que conservem "redes sociais de parentesco", "laços com a localidade" e com a "memória social" (FERREIRA, 2002, p. 33). Em “O admirável mundo novo de Alexander Chayanov", o campo é lembrado como "o lugar da preservação das tradições, da família, das raízes nacionais, da força comunitária espontânea" (ABRAMOVAY, 1998, p. 71).

O rural brasileiro é perpassado pelas diversas estratégias dos seus principais atores - os agricultores - para permanecerem neste espaço social. Trata-se também de um rural dinamizado por movimentos sociais que propugnam a volta à terra, tanto para os agricultores que não a possuem como para os migrantes rurais nas cidades, de primeira, segunda e terceiras gerações (...). Um rural onde os agricultores vêm pondo em prática estratégias de diversificação de seus estabelecimentos, de pluriatividade, de associativismo, de agroindustrialização em pequena escala, enfim, estratégias de valorização das oportunidades que o espaço local e a região oferecem para viabilizar sua reprodução tanto como agricultores quanto como rurais (FERREIRA, 2002, p. 39). 
O artigo"O Agroturismo e a Multifuncionalidade da Agricultura"(TRIVELLATO, 2019), apresentado no $11^{\circ}$ Congresso Brasileiro de Turismo Rural, buscou apontar a relação entre esses temas e a preservação ambiental e a valorização da cultura local.

\begin{abstract}
O agroturismo não é uma solução para problemas econômicos dos produtores e nem tampouco deve conduzir as propriedades à marginalização da importância da atividade produtiva. Ele pode, porém, constituir uma forte ferramenta para valorização, preservação e desenvolvimento local, contribuindo para ampliação do reconhecimento social e do poder político de agricultores familiares, assentados e comunidades tradicionais ao redor do mundo. A agricultura pode ser definida como multifuncional quando exerce uma ou várias funções além de seu papel principal de produzir alimentos e fibras. Estas funções adicionais podem incluir a contribuição da agricultura para a segurança alimentar a longo prazo, preservação das zonas rurais e do patrimônio cultural, conservação da biodiversidade e dos ecossistemas, manutenção das paisagens agrícolas e diversidade agrobiológica. Na medida em que o agroturismo pode apresentar grande potencial para fortalecer o desenvolvimento local, acreditamos que pode contribuir para as funções norteadoras da MFA na realidade rural brasileira: reprodução socioeconômica das famílias rurais; promoção da segurança alimentar das próprias famílias rurais e da sociedade; manutenção do tecido social e cultural; preservação dos recursos naturais e da paisagem rural (TRIVELLATO, 2019, p. 32-33).
\end{abstract}

Conforme Tatiana Colasante e Alini Nunes de Oliveira (2013), no $13^{\circ}$ Encuentro de Geógrafos de America Latina, "O turismo é, essencialmente, motivado por belas paisagens e o patrimônio histórico-cultural, pela sua monumentalidade e singularidade, desperta o interesse do turista" (COLASANTE; OLIVEIRA, 2013, p. 1). O mesmo pode ocorrer com as festas, enquanto expressões da cultura local, que atraem turista no sentido de "querer conhecer a cultura do local visitado, que muitas vezes difere do seu" (COLASANTE; OLIVEIRA, 2013, p. 5).

Para Angela Duarte Damasceno Ferreira (2002) A crise da agricultura moderna fez com que o "apelo em favor de uma agricultura verde, sustentável e de boas práticas agrícolas" ganhasse importância científica. (FERREIRA, 2002, p. 33). Este apelo "cresce em todos os países de capitalismo avançado, ao lado das novas concepções de áreas protegidas e parques" (op. cit.). O rural passou a ser reconhecido como "ponto de contato por excelência entre sociedade e natureza", tendo importância central nos embates sobre meio ambiente (op. cit.).

Para Dorow, Stern e Uller-Gómez (2015), os sistemas tradicionais de uso da terra, associados aos conceitos de "populações tradicionais" (ARRUDA, 2002, p. 274) e "campesinidade" (WOORTMANN, 1990) são importantes em termos econômicos, sociais 
e ecológicos. Isso porque o modelo de ocupação do território e uso de recursos naturais empregado pelas"populações tradicionais"é geralmente pautado por uma lógica sustentável, com fraca articulação com o mercado, produção destinada sobretudo ao autoconsumo, uso de mão-de-obra familiar e de tecnologias de baixo impacto (ARRUDA, 2002, p. 274). Além disso, as características de "campesinidade", geralmente encontradas os agricultores familiares, implicam numa forma de organização na qual o uso da terra é dependente do trabalho e da família (WOORTMANN, 1990).

Conforme Dorow, Stern e Uller-Gómez (2015), o conhecimento de técnicas tradicionais de produção é importante para as comunidades rurais, porque são mais do que apenas de técnicas de cultivo. Representam a resiliência (capacidade de retornar à agricultura, em caso de necessidade) desses grupos: garantia qualidade de vida, de permanência no campo, de manutenção de biodiversidade, de conservação cultural, de ordenação do território. Para Adams et. al. (2013), a perda desses conhecimentos impacta na diminuição da agrobiodiversidade; aumento do uso de agrotóxicos e fertilizantes sintéticos; redução da heterogeneidade da paisagem; maior dependência do mercado (comprometimento da renda) para aquisição de alimentos (ADAMS et. al., 2013).

Ademir Cazella e Bernard Roux (1999) defendem que "um verdadeiro processo de transformação do modelo agrícola implantado no pós-guerra está em curso". Sua origem seria o "questionamento dos modelos de desenvolvimento agrícola rural", como resultado das crises na área da alimentação e do modelo de desenvolvimento urbano. Verificouse aumento nas "exigências dos consumidores quanto à qualidade dos alimentos" e a legitimação das "formas de agricultura que não seguem os preceitos produtivistas". Enquanto isso, o desemprego e a "marginalização de uma parcela importante da população" teriam conduzido à revalorização do "meio rural enquanto espaço de vida e de trabalho" (CAZELLA; ROUX, 1999, p. 66-67).

\section{Espaços Rurais Brasieliros na Arte Näif de Marcelo Schimaneski: Valorização da Cultura Popular Rural Brasileira}

O artista Marcelo Schimaneski (SESC SP, 2018; SESC PIRACICABA, 2018), em suas obras, retrata a cidade de Ponta Grossa/PR e cenas de sua infância em chácaras e na região de Olarias/PR (PG CULTURA, 2011c). 
Acreditamos que seu trabalho permite um resgate da valorização da cultura popular rural brasileira. Descreve os detalhes do cotidiano do tecido social e cultural no rural agrário e familiar do Brasil. Nesse sentido, suas obras retratam o mundo justo doméstico de Luc Boltanski e Laurent Thévenot (1991), associado à tradição, à proximidade, ao afetivo, à confiança. Mas também o apelo a uma ordem justa ecológica.

Com a sociologia das justificações, Boltanski e Thévenot (1991) definiram seis grupos de princípios de justiça: inspirada, renome, doméstica, cívica, mercantil e industrial. Estes princípios legitimariam as opções das sociedades por determinados padrões de produção, consumo, hierarquias, convivência: o que é justo num determinado grupo/mundo, é justificado, ou seja, legítimo.

Os mundos industriais e mercantis são usados para legitimar o capitalismo contemporâneo e, portanto, a modernização da agricultura. Os mundos doméstico, cívico e ecológico são usados para construir argumentos para a crítica contra a agricultura industrialmercantil e propor modelos agroalimentares diferentes do produtivista (TORUNSKY, 2019; MARQUES; DE GASPARI; ALMEIDA, 2017).

O mundo doméstico favorece agriculturas alternativas, sobretudo as familiares, pois é pautado pelas lógicas de justiça familiar, valorizando a tradição, proximidade, zelo, confiança (TORUNSKY, 2019).

O mundo cívico reconhece os valores de uma democracia participativa, prega que as relações entre os indivíduos devem ser concebidas com ampla participação, atendendo ao interesse geral (MARQUES; DE GASPARI; ALMEIDA, 2017). Nesse sentido, promove modelos agroalimentres pautados pela participação social, favorecendo as OCSs (Organizações de Controle Social) e CSAs (Comunidades que Sustentam a Agricultura) (TORUNSKY, 2019).

Boltanski e Thévenot (1991) apontaram que, conforme as sociedades se desenvolvem, podem surgir novos mundos justos além daqueles seis. Hoje, o fortalecimento do debate sobre o impacto das ações humanas sobre o meio ambiente e de propostas para um desenvolvimento sustentável fomentaram o surgimento de uma ordem justa ecológica.

A ordem justa ecológica preza por uma forte preocupação com as gerações futuras e com a preservação dos recursos. Busca consolidar um modo de vida, e, portanto, um modelo agroalimentar, no qual evitam-se desperdícios ou ostentação (TORUNSKY, 2019; MARQUES; DE GASPARI; ALMEIDA, 2017).

Nas próximas páginas, apresentamos seis obras Naïf de Marcelo Schimaneski: “Casa 
da Vó do Celso" (PG CULTURA, 2011b);"Casa da Vó Dica"(PG CULTURA, 2011a);"Pesque-pague" (GALERIA JACQUES ARDIES, 2019b); “Ágape da Marcela” (GALERIA JACQUES ARDIES, 2019a); "Alegria na favela" (GALERIA JACQUES ARDIES, 2017); “Os Girassóis” (SABER CULTURAL, 2019).

Estas foram selecionadas porque acreditamos que capturam cenas do cotidiano de populações agrícolas rurais brasileiras, com detalhes de suas características particulares, sendo possível identificar nelas aspectos da multifuncionalidade da agricultura (MFA) familiar brasileira. Acreditamos que a identificação de aspectos da MFA, expressas pela valorização da identidade dos lugares retratados, podem ser fatores para contribuir com a preservação ambiental e cultural de espaços rurais como estes.

Figura 3 - "Casa da Vó do Celso" (esquerda) e "Casa da Vó Dica" (direita), ambas de Marcelo Schimaneski. Expressões da ruralidade e da vida cotidiana no interior do Paraná (Brasil).
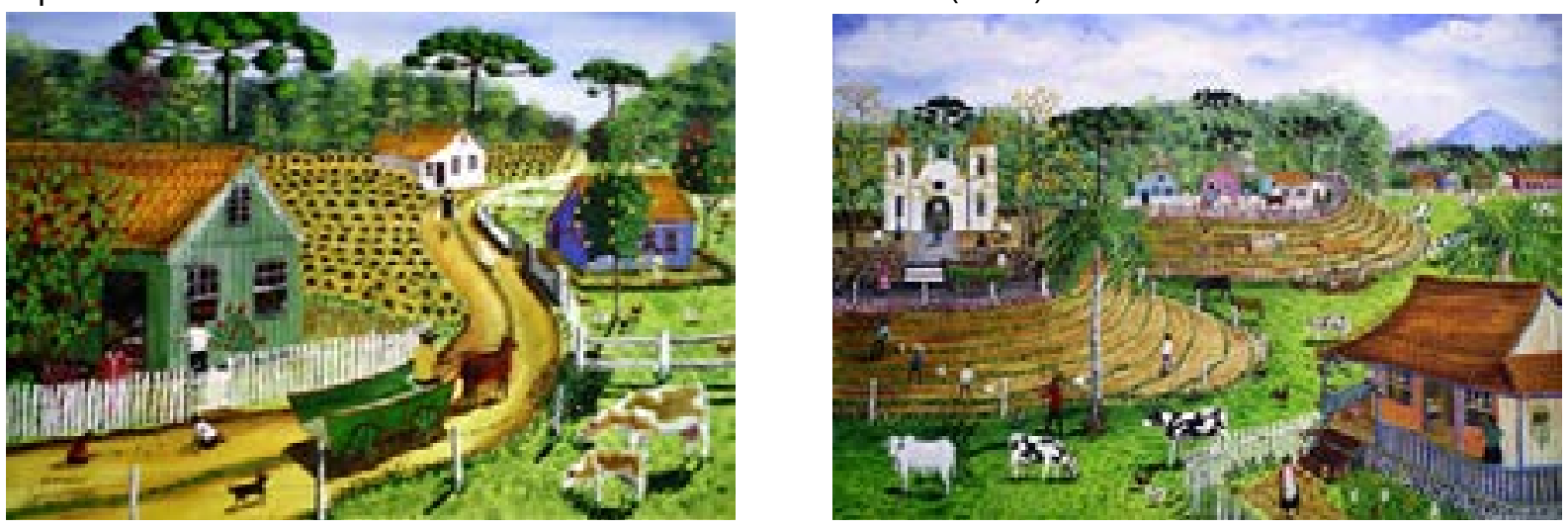

Fonte: PG Cultura (2011b; a).

Na Figura 3, as obras "Casa da Vó do Celso" (esquerda) e "Casa da Vó Dica" (direita), sugerimos a possibilidade de encontrarmos expressões da vida cotidiana no interior do estado do Paraná, Brasil. Destacamos a proximidade entre as casas, diversidade de cultivos e criações animais. São realizadas diversas tarefas no mesmo espaço: criação, lavoura, comércio (distribuição).

Concomitantementeà agricultura e pecuária, está retratada a preservação da floresta nativa, representada pelas Araucárias (SAHR; CUNHA, 2005). Percebemos a diversidade do tecido social e cultural (CARNEIRO; MALUF, 2003) na presença da igreja, na interação entre os indivíduos retratados, seja trabalhando juntos, trocando produtos ou apenas conversando (impressões do autor). 
Figura 4 - "Pesque-pague", de Marcelo Schimaneski. Manutenção do tecido social e cultural, reprodução socieconômica das famílias rurais, segurança alimentar, heterogeneidade da paisagem.

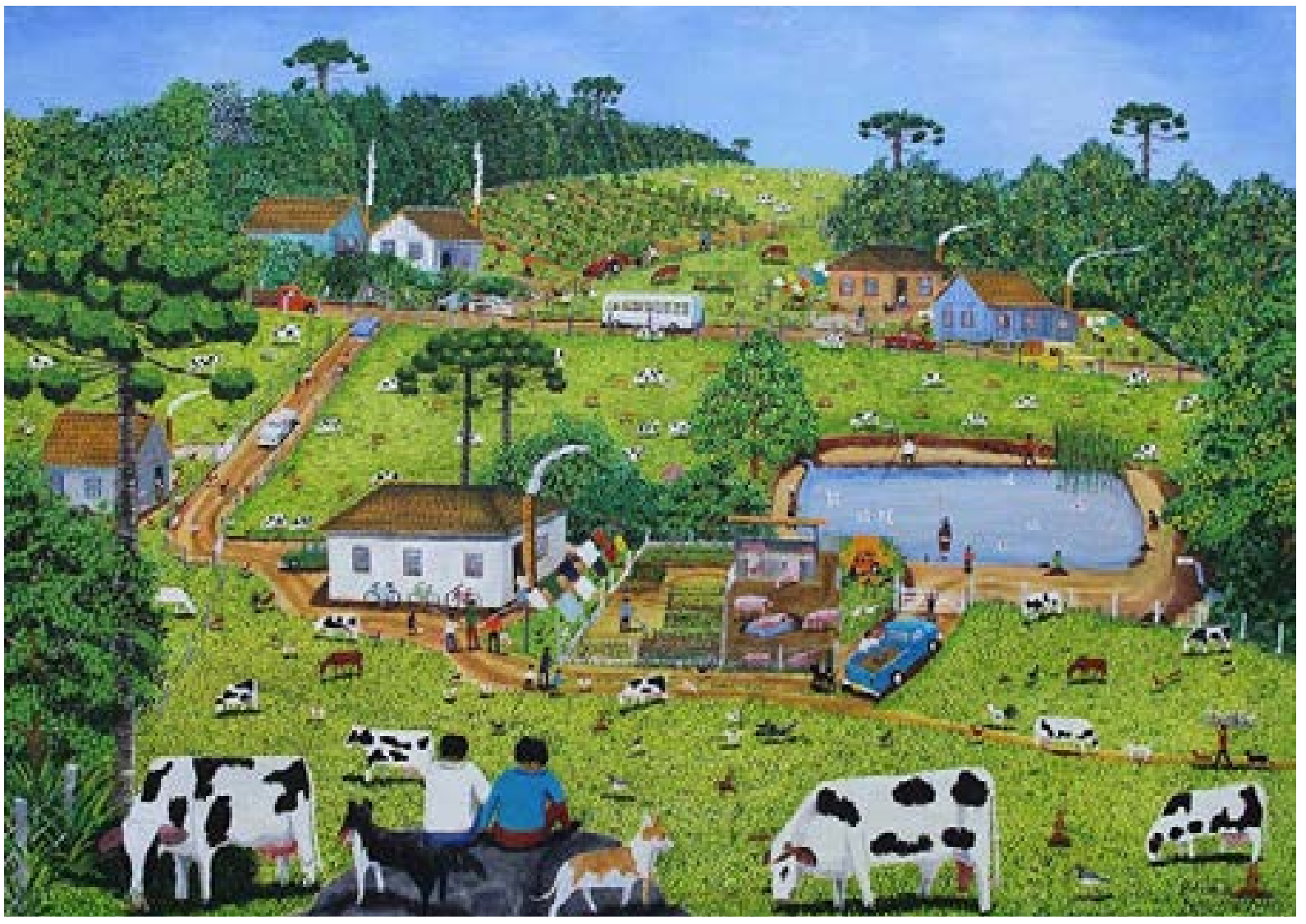

Fonte: Galeria Jacques Ardies (2019b).

Na Figura 4, a obra "Pesque-Pague", identificamos aspectos das expressões da multifuncionalidade da agricultura (MFA) na realidade rural brasileira, apontadas por Maria José Carneiro e Renato Maluf (2003), tais como a diversidade de criação de animais, assegurando e reprodução socioeconômica das famílias rurais e promovendo a segurança alimentar das próprias famílias rurais e da sociedade.

A circulação de veículos e pessoas manifesta-se como expressão da manutenção do tecido social e cultural, a nosso entender. A presença de florestas no entorno do espaço revela a heterogeneidade da paisagem rural, assim como a preservação dos recursos naturais (CARNEIRO; MALUF, 2003). 
Figura 5 - "Ágape da Marcela", de Marcelo Schimaneski. Valorização dos costumes locais: no canto esquerdo, churrasco tradicional característico da região retratada pelo artista em suas obras - Ponta Grossa e Olarias, no estado brasileiro do Paraná.

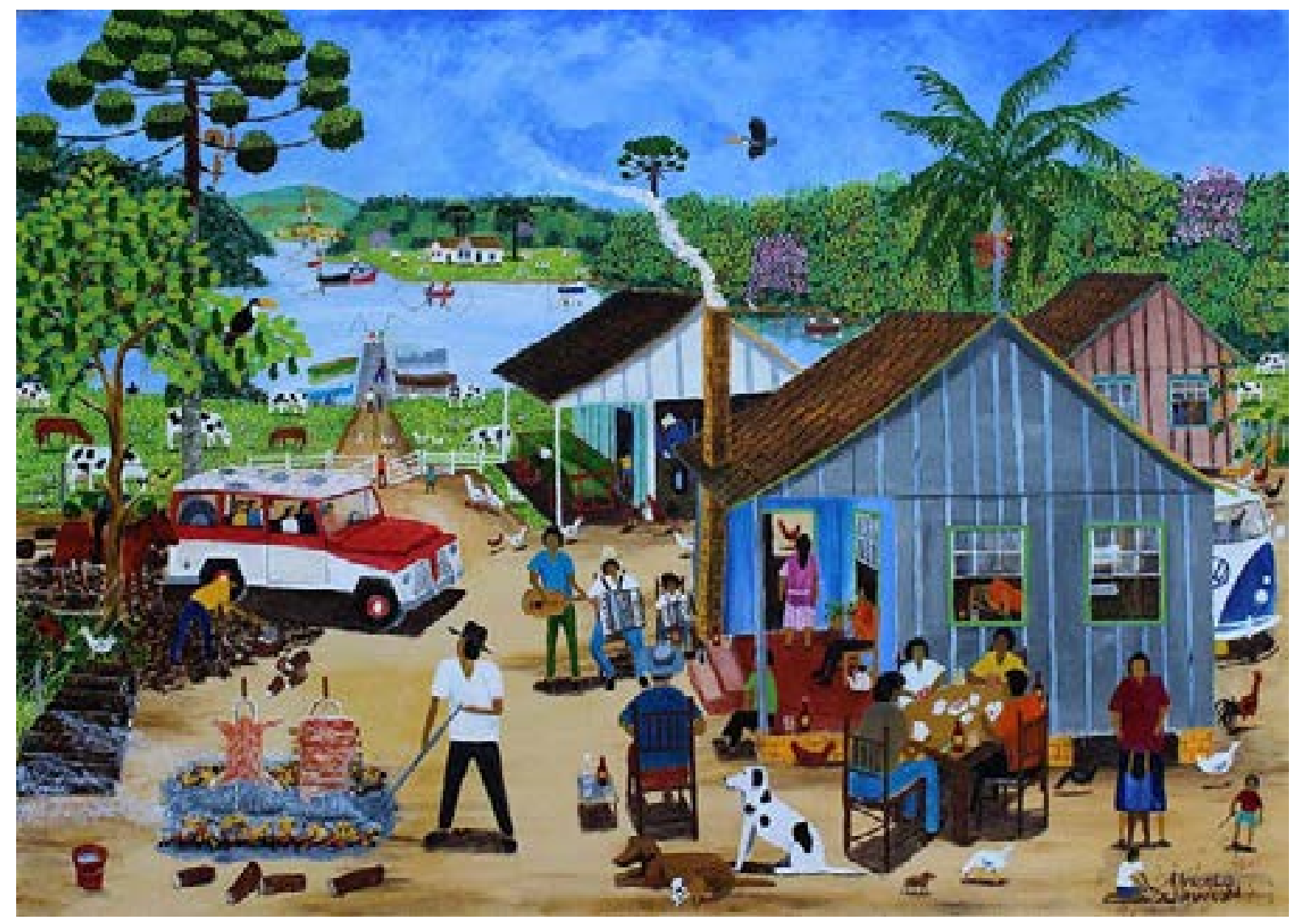

Fonte: Galeria Jacques Ardies (2019a).

Em "Ágape da Marcela" (Figura 5), identificamos as espécies de aves, remetendo ao papel das populações rurais na preservação da avifauna (ANDRADE et al., 2014). Destacamos a construção das casas, as pessoas sentadas à mesa, os carros que são úteis para o meio rural por comportarem os produtos para comercialização, insumos, ração.

Identificamos a valorização dos costumes locais: churrasco tradicional no canto esquerdo e, ao centro, músicos tocando instrumentos tradicionais. Colasante (2015) trata do tradicionalismo gaúcho presente no estado do Paraná. Sua pesquisa revelou que os Centros de Tradição Gaúcha (CTGs) são vistos como "ambientes familiares, nos quais os gaúchos podem reavivar suas tradições e também passar valores aos filhos" (COLASANTE, 2015, p. 8-9). Muitos CTGs no Norte do Paraná foram criados para que se tivesse um "espaço de vivência para difundir os valores tradicionalistas", sendo frequentes os rodeios, festas como Costeladas e Churrasco Fogo de Chão para apreciar a culinária gaúcha (op. cit., p. 8). 0 tradicionalismo gaúcho é visto como "algo benéfico e que deve ser praticado, sobretudo, às 
novas gerações a fim de que os valores não se percam" (op. cit., p. 10).

A partir disso, podemos compreender o imaginário coletivo que muitos gaúchos carregam em si quando migram para outras regiões do país, pois, acabam trazendo consigo essa ideologia de preservar a tradição em diversos territórios, de forma a reproduzir seus valores. Verificamos, portanto, que estes grupos sociais possuem uma territorialidade baseada em comportamentos e ações que estão condicionados à múltiplos aspectos como políticos, econômicos e culturais (COLASANTE, 2015, p. 10).

Figura 6 - "Alegria na favela", de Marcelo Schimaneski. Expressão da cultura popular local.

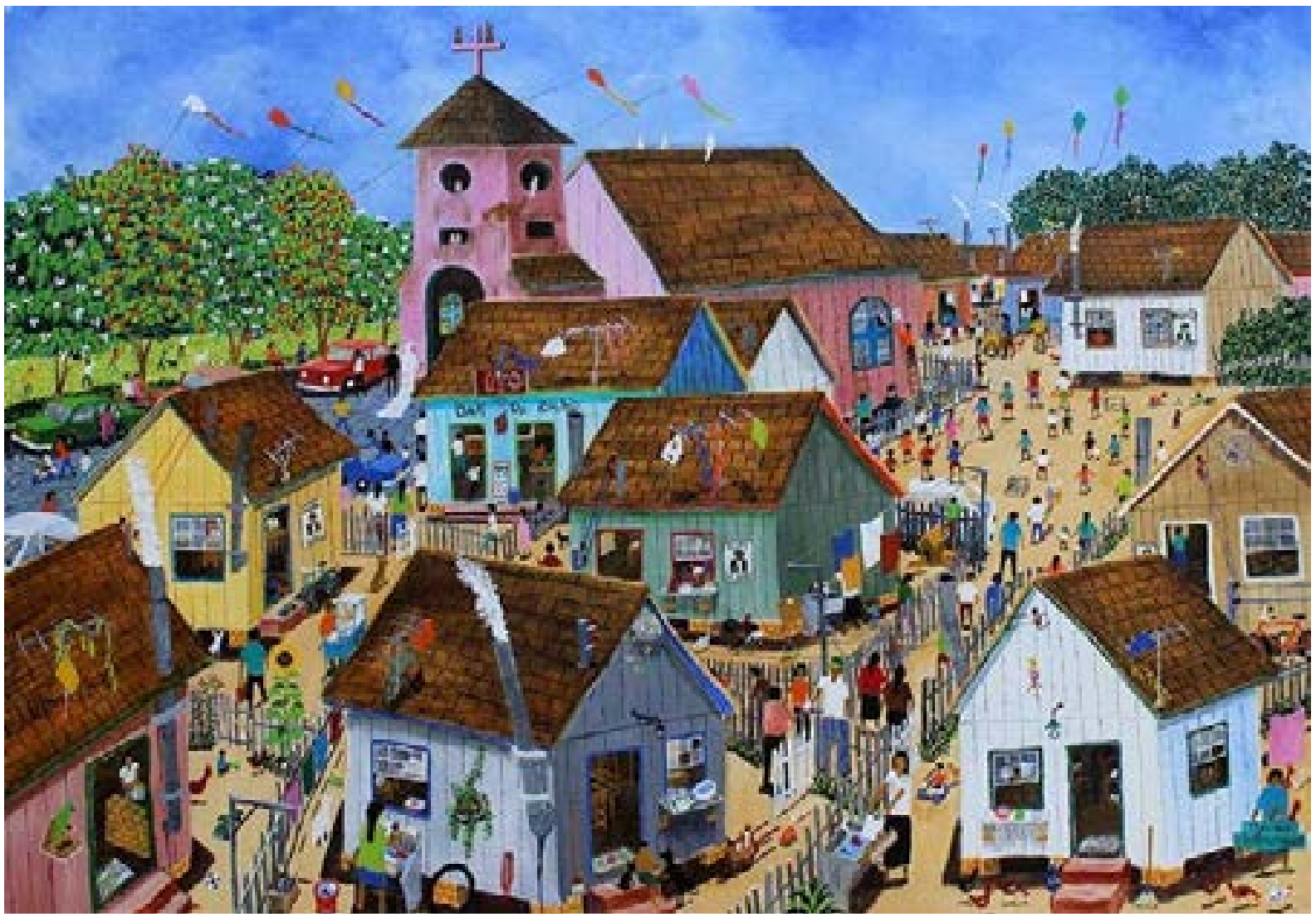

Fonte: Galeria Jacques Ardies (2017).

Na Figura 6, "Alegria na favela", de Marcelo Schimaneski, identificamos elementos de expressão da cultura popular local: pipas e a decoração da festa; a forte presença da igreja, localizada no centro da pintura; espaço de convivência ao lado da igreja, onde as pessoas circulam, crianças brincam; construção típica das casas no interior do Paraná, Brasil; proximidade entre as casas, separadas por pequenas cercas de madeira, favorecendo a convivência próxima, o diálogo entre os vizinhos e a criação das crianças pela comunidade 
como um todo. Percebem-se as pessoas da comunidade envolvidas na organização do evento: cozinhando, carregando lenha (ANTONIO; CARDOZO, 2008; ANDRADE, 2005).

Figura 7 - “Os Girassóis", de Marcelo Schimaneski. Fixação das pessoas no campo.

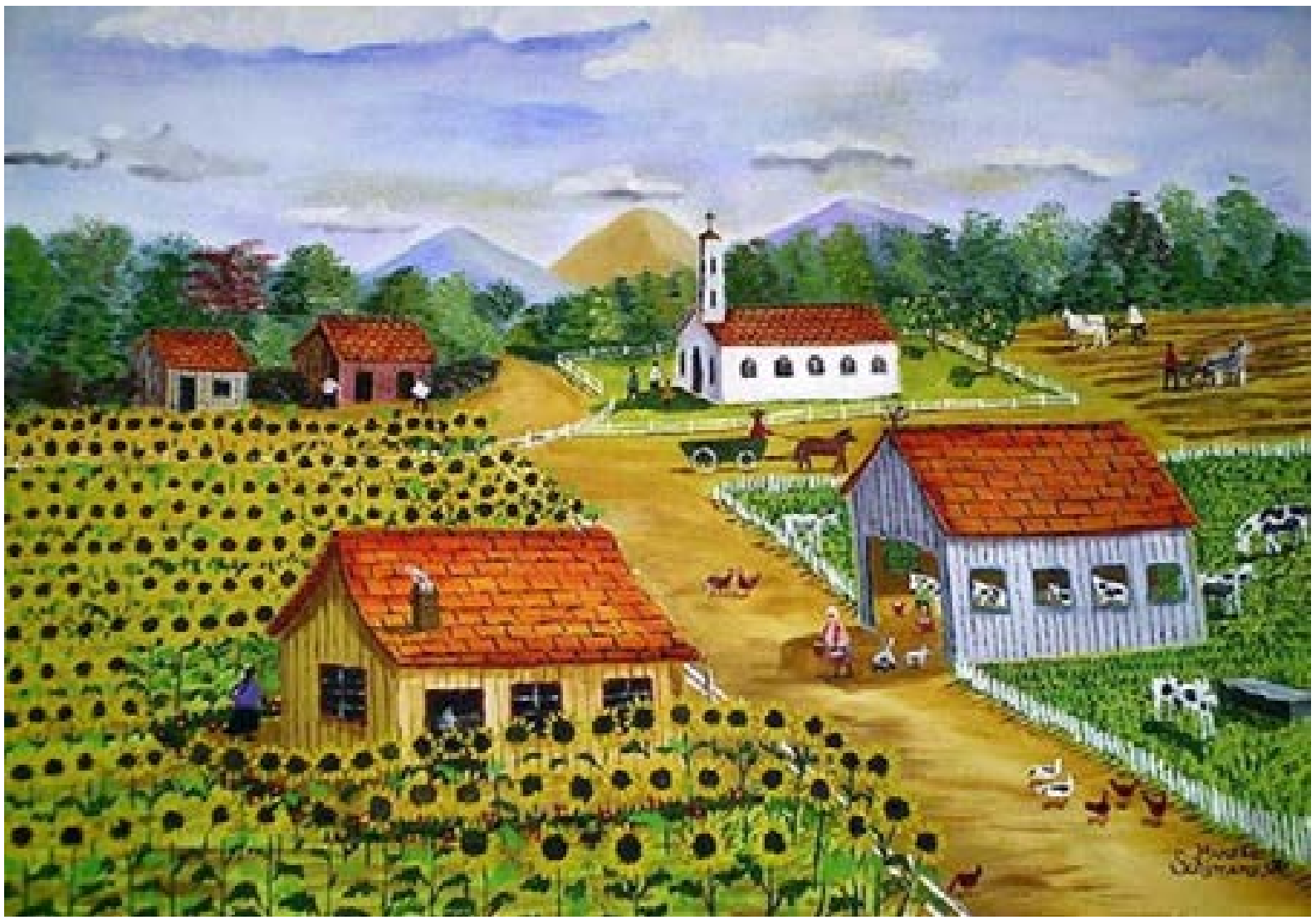

Fonte: Saber Cultural (2019).

Na Figura 7, em "Os Girassóis", notamos a fixação das pessoas no campo (FERREIRA, 2002). Trata-se de um espaço rural (ao fundo uma paisagem serrana, precedida por uma vasta floresta), onde existem galpões para criação de animais e armazenamento. Assim como em "Alegria na favela", (Figura 6), destacamos a presença da igreja. A existência de uma capela demarca a presença das pessoas nesse espaço, sua fixação, permanência.

\section{Considerações Finais}

A arte Naïf do artista Marcelo Schimaneski retrata cenas do cotidiano de espaços rurais na região das cidades paranaenses de Ponta Grossa e Olarias. Acreditamos que é possível identificar em suas obras aspectos da multifuncionalidade da agricultura (MFA) 
familiar brasileira.

O conceito de MFA permite reconhecer que os seres humanos tem importante papel na preservação ambiental e que a permanências das pessoas nas áreas rurais está fortemente atrelada à manutenção de sua cultura local.

Acreditamos que as obras Naïf desse artista valorizam a identidade dos lugares retratados, podendo corroborar com a preservação ambiental e cultural de espaços rurais como os retratados.

\section{Referências}

ABRAMOVAY, Ricardo. O admirável mundo novo de Alexander Chayanov. Estudos Avançados, v. 12, n. 32, p. 69-74, 1998.

ABRAMOVAY, Ricardo. Transformações na vida camponesa: o Sudoeste Paranaense. Dissertação (Mestrado) - Universidade de São Paulo, São Paulo, 1981.

ADAMS, C. et. al. Diversifying Communities Incomes and Losing Landscape Complexity in Quilombola Shifting Cultivation Communities on the Atlantic Rainforest (Brazil). Human Ecology, Columbus, v. 41, n. 1, p.119-137, 2013.

ANDRADE, H. M. L. S. et. al. Conhecimento e interações dos agricultores do semiárido pernambucano em relação à avifauna local. VI Encontro da Rede de Estudos Rurais "Desigualdade, exclusão e conflitos nos espaços rurais": Campinas: UNICAMP. 2014.

ANDRADE, José Antônio de. As unidades de paisagens e os sistemas de produção agrícolas no município de Floraí-PR. 2005. 116p. Dissertação (Mestrado em Geografia). Maringá: Programa de Pós-graduação em Geografia, Universidade Estadual de Maringá. 2005.

ANTONIO, Fábio Maurício; CARDOZO, Poliana Fabíula. Turismo étnico no meio rural: possibilidades para a comunidade de imigrantes ucranianos de Linha Esperança-Prudentópolis/PR. Voos Revista Polidisciplinar Eletrônica da Faculdade Guairacá, v. 4, n. 1, 2008.

ARRUDA, R. S. V. Populações tradicionais e a proteção dos recursos naturais em unidades de conservação. In: DIEGUES, A. C. (Org.). Etnoconservação. Novos rumos para a proteção da natureza nos trópicos. 2. ed. São Paulo: Annablume; USP, 2002.

BERGAMASCO, Sonia Maria Pessoa Pereira; BUENO, Osmar de Carvalho. Agricultura familiar e poder local: um exercício de cidadania. In: FERREIRA, Angela Duarte Damasceno; BRANDENBURG, Alfio. (Orgs.). Para pensar outra agricultura. 2a edição. Curitiba: Editora UFPR, p. 119 -149, 2008.

BOLTANSKI, Luc; THÉVENOT, Laurent. De la justification. Paris: Gallimard, 1991.

BRANDENBURG, Alfio. Colonos: subserviência e autonomia. In: FERREIRA, Angela Duarte Damasceno; BRANDENBURG, Alfio. (Orgs.). Para pensar outra agricultura. 2a edição. Curitiba: Editora UFPR, p. 81-118, 2008. 
CARNEIRO, Maria José; MALUF, Renato Sergio. Multifuncionalidade da agricultura familiar. In.: BOTELHO FILHO, Flávio Borges (org.). Agricultura Familiar e Desenvolvimento Territorial -Contribuições ao Debate. Brasília: Universidade de Brasília, Centro de Estudos Avançados Multidisciplinares, Núcleo de Estudos Avançados. v. 5, n. 17, p. $43-58,2005.168$ p.

CARNEIRO, Maria José; MALUF, Renato Sergio. Para além da produção: multifuncionalidade e agricultura familiar. Rio de Janeiro: Mauad, 2003, 230p.

CAZELLA, Ademir Antonio; BONNAL, Philippe; MALUF, Renato Sergio (orgs.). Agricultura familiar: multifuncionalidade e desenvolvimento territorial no Brasil. Rio de Janeiro: Mauad X, 2009.

CAZELLA, Ademir Antonio; ROUX, Bernard. Agribusiness em questão: a emergência da agricultura multifuncional. Estudos sociedade e agricultura, v. 13, n. 10, p. 46-69, 1999.

COLASANTE, Tatiana. A identidade territorial dos migrantes gaúchos no Paraná. In: Encuentro de Geógrafos de América Latina "Por uma America Latina unida y sustentable", 15., 2015, Cuba. Anais Eletrônicos... Cuba: Observatorio Geográfico de América Latina. 2015. 13p. Disponível em: <http:// observatoriogeograficoamericalatina.org.mx/egal15/Geografiasocioeconomica/Geografiadelapoblacion/52. pdf >. Acesso em: 7 dez. 2020.

COLASANTE, Tatiana; OLIVEIRA, Alini Nunes de. Turismo e cultura: um estudo sobre o patrimônio históricocultural de Londrina como atrativo. In: Encuentro de Geógrafos de América Latina "Estableciendo puentes en la geografía de Latinoamérica", 15., 2015, Costa Rica. Anais Eletrônicos... Costa Rica: Observatorio Geográfico de América Latina. 2013. 17p. Disponível em: <http://www.observatoriogeograficoamericalatina.org.mx/egal13/ Geografiasocioeconomica/Geografiaturistica/27.pdf>. Acesso em: 7 dez. 2020.

COURLET Claude; PECQUEUR Bernard; SOULAGE, Bernard. Industries et dynamiques de territories. Paris. Revue d'économie industrielle, v. 64, n. 1, p. 7-21, 1993.

DEL CID, Alma Lorena. El arte naif como generador de desarrollo territorial. ECO Revista Académica: Gerencialidad Socio-empresarial. Facultad de Ciencias Económicas y Empresariales. Universidad Rafael Landívar, Guatemala, n. 5, p. 17-29, set. 2010.

DEL CID, Alma Lorena. Potentiality of symbolic capital in the rural space as generator of territorial development. Agronomía Colombiana, v. 29, n. 1, p. 115-123, 2011.

DOROW, Reney; STERN, Ivonete Lenir; ULLER-GÓMEZ, Cíntia. Da reinterpretação de sistemas tradicionais de uso da terra à construção social de mercados com os agricultores familiares da roça de toco de Biguaçu-SC. Novos Cadernos NAEA, v. 18, n. 1, p. 65-87, 2015.

DOS SANTOS, José Marcelo Costa; DE OLIVEIRA MOLINARI, Paula Maria Aristides. Naïf: Beleza e Simplicidade como Expressões da Cultura. Form@ re - Revista do Plano Nacional de Formação de Professores da Educação Básica/Universidade Federal do Piauí, Teresina, v. 4, n. 1, p.3-7, jan./jun. 2016.

FERREIRA, Angela Duarte Damasceno. Processos e sentidos sociais do rural na contemporaneidade: indagações sobre algumas especificidades brasileiras. Estudos sociedade e agricultura, v. 10, n. 1, p. 28-46, 2002.

FERREIRA, Angela Duarte Damasceno; ZANONI, Magda. Outra agricultura e a reconstrução da ruralidade. In: FERREIRA, Angela Duarte Damasceno; BRANDENBURG, Alfio. (Orgs.). Para pensar outra agricultura. $2^{\text {a }}$ edição. Curitiba: Editora UFPR, p. $119-149,2008$.

FRANCO ALVES, Arilde; MALAGODI, Edgard Afoinso. Multifuncionalidade da Agricultura: retórica ou ferramenta de análise do Desenvolvimento Rural? REVISTA ALASRU Análisis Latinoamericano del Medio Rural. Nueva Época, n.9, p. 117-137, 2014.

GALERIA JACQUES ARDIES. “Ágape da Marcela”, de Marcelo Schimaneski. Disponível em: <http://ardies.com/ marcelo-schimaneski/>. Acesso em: 4 nov. 2019a. 
GALERIA JACQUES ARDIES. “Alegria na favela”, de Marcelo Schimaneski, 29 jun. 2017. Disponível em: <https:// www.facebook.com/galerianaif/photos/a.582422021796594/1431603136878474/?type=3\&theater $>$. Acesso em: 4 nov. 2019.

GALERIA JACQUES ARDIES. "Pesque-pague", de Marcelo Schimaneski. Disponível em: <http://ardies.com/ marcelo-schimaneski/>. Acesso em: 4 nov. $2019 \mathrm{~b}$.

LACERDA, Tatiana Ferreira Nobre; MORUZZI MARQUES, Paulo Eduardo. Agricultura orgânica, representação territorial e reprodução social da agricultura familiar: os agricultores ecologistas da Encosta da Serra Geral em Santa Catarina. Revista Ruris, v. 2, p. 137-158, 2008.

LAURENT, Catherine. La multifunctionalité de l'agriculture. Paris: Inra-SAD, 2000.

MARQUES, Paulo Eduardo Moruzzi; DE GASPARI, Luciane; ALMEIDA, Bruna. Organização de Controle Social (OCS) e engajamento agroecológico das famílias do assentamento Milton Santos no estado de São Paulo. Estudos Sociedade e Agricultura, p. 545-560, 2017.

MEA - Millennium Ecosystem Assessment. Ecosystem and human well-being: biodiversity synthesis. World Resources Institute, Washington, DC, 2005a, 86p.

MEA - Millennium Ecosystem Assessment. Ecosystems and Human Well-being: Synthesis. Island Press, Washington, DC, 2005b, 137p.

MORUZZI MARQUES, Paulo Eduardo; DE LUCAS, Ademir;TRIVELLATO, Gabriela Maria Leme. O Papel da Extensão Universitária no apoio à Agricultura Familiar no município de São Pedro/SP. Rev. Cult. Ext. USP, São Paulo, v. 18, p. 13-23 nov, 2017.

PG CULTURA. "Casa da Vó Dica", de Marcelo Schimaneski, 13 ago. 2011a. Disponível em: <http://pgcultura. blogspot.com/2011/08/conheca-nossos-artistas-marcelo.html>. Acesso em: 4 nov. 2019.

PG CULTURA. "Casa da Vó do Celso", de Marcelo Schimaneski, 13 ago. 201 1b. Disponível em: <http://pgcultura. blogspot.com/2011/08/conheca-nossos-artistas-marcelo.html>. Acesso em: 4 nov. 2019.

PG CULTURA. Conheça Nossos Artistas - Marcelo Schimaneski, 13 ago. 2011c. Disponível em: <http:// pgcultura.blogspot.com/2011/08/conheca-nossos-artistas-marcelo.html>. Acesso em: 4 nov. 2019.

RÉMY, Jacques. Um caminho sinuoso e semeado de espinhos. Os agricultores franceses: da especialização e intensificação da produção à multifuncionalidade e ao desenvolvimento sustentável. Estudos Sociedade e Agricultura, Rio de Janeiro, CPDA, v. 12, fasc. 1, 2005.

ROUX, Bernard; FOURNEL, Estelle. Multifuncionalidade e emprego nos estabelecimentos rurais franceses: um estudo nas zonas montanhosas de Languedoc Roussillon. Para além da produção: multifuncionalidade e agricultura familiar. Rio de Janeiro: Mauad, p. 169-199, 2003.

SABER CULTURAL. "O Girassóis", de Marcelo Schimaneski. Disponível em: <http://www.sabercultural.com/ template/ArteBrasilPintores/SchimaneskiMarcelo1.html>. Acesso em: 4 nov. 2019.

SAHR, Cicilian Luiza Löwen; CUNHA, Luiz Alexandre Gonçalves. O significado social e ecológico dos faxinais.: Reflexões acerca de uma política agrária sustentável para a região da Mata com Araucária no Paraná. Emancipação, v. 5, n. 1, p. 89-104, 2005.

SCHNEIDER, Sergio. A pluriatividade como estratégia de reprodução social. Estudos Sociedade e Agricultura, Rio de Janeiro, CPDA/UFRRJ, n. 16, p. 164-184, 2002.

SESC PIRACICABA. Resultado obras e Artistas Selecionados Bienal Naïfs Do Brasil 2018. 10 mai 2018. Disponível em: <http://www.homedecore.com.br/wp-content/uploads/2018/05/Bienal-Na\%C3\%AFfs-doBrasil-2018_Resultado-Obras-e-Artistas-Selecionados_Tabela.pdf >. Acesso em: 17 mar. 2019. 
SESC SP. Vem aí a 14a Bienal Naïfs do Brasil. 17 jul 2018. Disponível em: <https://www.sescsp.org.br/online/ artigo/12292_VEM+AI+A+14+BIENAL+NAIFS+DO+BRASIL>. Acesso em: 17 mar. 2019.

TORUNSKY, Flavia. Justificativas em torno das Comunidades que Sustentam a Agricultura: um estudo de caso da CSA São Carlos/SP. Dissertação (Mestrado) - Escola Superior de Agricultura "Luiz de Queiroz", Centro de Energia Nuclear na Agricultura. Piracicaba, 2019, 2137p.

TRIVELLATO, Gabriela Maria Leme; DOS SANTOS, Mayara Araújo. O Papel dos Seres Humanos na Manutenção dos Ecossistemas. Revista Relicário, v. 6, n. 11, p. 104-116, 2019.

TRIVELLATO, Gabriela Maria Leme. O Agroturismo e a Multifuncionalidade da Agricultura. In: Congresso Brasileiro de Turismo Rural, 11., 2019, Piracicaba, SP, Brasil. Anais... Piracicaba: FEALQ, 2019. p. 17-37.

WOORTMANN, Klass. Com parente não se neguceia: O campesinato como ordem moral. Anuário Antropológico, n. 87, p. 11-73, 1990. 